\title{
The mechanical and thick section bending behavior of friction stir processed aluminum plate
}

\author{
D. Hulbert, ${ }^{\mathrm{a}, *}$ C. Fuller, ${ }^{\mathrm{b}}$ M. Mahoney ${ }^{\mathrm{b}}$ and B. London ${ }^{\mathrm{c}}$ \\ ${ }^{\mathrm{a}}$ Division of Materials Science, University of California, Davis, CA 95616, USA \\ ${ }^{\mathrm{b}}$ Rockwell Science Center, Thousand Oaks, CA 91360, USA \\ ${ }^{\mathrm{c}}$ Department of Materials Engineering, California Polytechnic University, San Luis Obispo, CA 93407, USA
}

Friction stir processing (FSP) 2519-T87 aluminum plate results in enhanced ductility, 25\% strain at fracture. However, the yield strength in the FSP zone drops to $175 \mathrm{MPa}$ from $\sim 400 \mathrm{MPa}$. Actively cooling the plate during FSP increases the yield strength to $185 \mathrm{MPa}$ and decreases ductility to $20 \%$ strain at fracture. Thick bending of a plate of the alloy was demonstrated after the surface was subjected to FSP.

Keywords: Friction stir processing; Severe plastic deformation; Aluminum alloy; Mechanical properties testing; Plate bending

Friction stir processing (FSP) is a variation of friction stir welding (FSW), a solid-state thermomechanical joining process invented at The Welding Institute in the UK [1-4]. Since its inception FSW has shown great promise in joining many high strength aluminum alloys that have in the past proven difficult to join using more conventional techniques such as arc welding [5]. Presumably, all materials that can be friction stir welded could be subjected to FSP due to the similarities between the two processes. In fact, the only major difference between FSW and FSP is the presence of a joint within the material(s) during FSW operations.

Additionally, FSP shows promise as a forming aid if used prior to certain forging operations. For example, the bending of thick sections $(>2.5 \mathrm{~cm})$ of material at room temperature has proven challenging. As this study will show, by FSP the tensile strained surface of a plate, large amounts of deformation become possible. Overall, both FSP and FSW are relatively new and novel techniques that will most likely see increased use in a variety of manufacturing environments over the next few decades.

The material tested in this investigation is 2519-T87 aluminum plate. 2519 aluminum is an exceptionally strong wrought aluminum-copper alloy with a yield strength and ultimate tensile strength of over 420 and $470 \mathrm{MPa}$ respectively, making it stronger than many

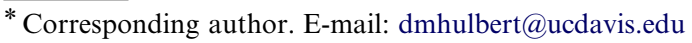

structural steels [4]. Additionally, 2519-T87 has substantial ductility of over $10 \%$ at room temperature [6]. Applications for this alloy range from ballistic armor plating to fuselage components for commercial aircraft. Unfortunately, due to the dispersion strengthening effect of the copper precipitates, the alloy exhibits poor weldability, making it difficult to join.

FSP can expand the horizons of shaping 2519 and other alloys by greatly enhancing formability. In general, it is believed that microstructural defects (inclusions, pores, cracks, etc.) are broken apart and grains are recrystallized and refined to an equiaxed morphology. The microstructure then becomes much more damage tolerant and susceptible to forming operations at lower temperature $[7,8]$. Once such forming operation is the thick section bending of large plates $(>2 \mathrm{~cm}$ thick) at room temperature. This capability carries with it many obvious advantages, including the ability to manufacture shapes that were previously impossible to make. Additionally, the savings of resources, including material, energy and time, are substantial. Shaping thin sections or sheets at room temperature is relatively easy because the tensile strains at the surface of the material are small given the relative short distance between the surface and the neutral axis. As thickness increases huge tensile strains accumulate at the surface of the part, making the nucleation and propagation of defects much more likely. The end result is that forging thick sections of alloys becomes increasingly difficult especially at room temperature. FSP helps mitigate this problem. 
Table 1. FSP details

\begin{tabular}{ll} 
Plate thickness $(\mathrm{cm})$ & 2.54 \\
Tool velocity $\left(\mathrm{cm} \mathrm{min}{ }^{-1}\right)$ & 10.16 \\
Rotation $(\mathrm{RPM})$ & 600 \\
Tool angle relative to work piece $\left({ }^{\circ}\right)$ & 3 \\
Approximate vertical force $(\mathrm{kg})$ & 2948 \\
Approximate horizontal force $(\mathrm{kg})$ & 170 \\
Width of each pass $(\mathrm{mm})$ & 3.16 \\
Depth of each pass $(\mathrm{mm})$ & 7 \\
Shoulder to shoulder width of FSP zone $(\mathrm{cm})$ & 9.53 \\
Pin to pin width of FSP zone $(\mathrm{cm})$ & 7.94 \\
\hline
\end{tabular}

Inch thick Alcoa 2519-T87 aluminum plate (Alcoa Mill Products, Inc. Bettendorf, Iowa) was subjected to FSP. The details of the processes are shown in Table 1. The tool geometry was a standard threaded screw pin.

The actively cooled FSP used the same parameters outlined above. In order to achieve active cooling, tap water was sprayed onto the plate during FSP using a squirt bottle. Additionally, cool water $\left(\sim 20^{\circ} \mathrm{C}\right)$ was circulated through a copper anvil located beneath the work piece.

Following FSP of both conventionally processed and actively cooled plates, $3.81 \mathrm{~cm} \times 29.21 \mathrm{~cm}$ sections of plate were bent at room temperature at a rate of $0.254 \mathrm{~mm} \mathrm{~s}^{-1}$ using a 363 metric ton press. This was done to demonstrate the thick section bending behavior FSP induces in the alloy.

Mechanical testing was conducting using micro-hardness and tensile testing. For all hardness tests $50 \mathrm{~g}$ of force was applied with a four-sided pyramid indenter in contact with the plate for at least $5 \mathrm{~s}$.

Eighteen tensile specimens were machined and tested for both actively cooled and conventionally processed plates for a total of 36 specimens. Six specimens were taken from the FSP zone of each plate, six from the mid-plane of each plate and six from near the bottom of each plate adjacent to the anvil. The specimens were prepared according to ASTM standards using the E8 sub-size specimen testing method [9]. A tabletop Instron, Model \#3369 tensile tester with a $50 \mathrm{kN}$ loading capacity was used in all tensile tests. The data were gathered using a PC computer along with the Merlin software that accompanied the tensile tester. The specimens were initially pulled at $5 \mathrm{~mm} \mathrm{~min}^{-1}$; this rate was increased to $25 \mathrm{~mm} \mathrm{~min}^{-1}$ once the specimens reached $10 \%$ strain. All tests were performed at $20 \pm 3{ }^{\circ} \mathrm{C}$.

Metallography was performed using an optical microscope on both conventionally processed and ac- tively cooled material, as well as the as-received aluminum 2519-T87 plates. All 2519 aluminum specimens were swab etched using Kellar's reagent.

The as-received microstructure had a lamellar morphology with large elongated grains due to the rolling during manufacturing and an approximate grain size of $150 \mu \mathrm{m} \times 35 \mu \mathrm{m}$. Additionally, the copper rich second phase of the alloy was abundantly present, especially along the grain boundaries. Because 2519 contains as much as $6.4 \mathrm{wt} . \% \mathrm{Cu}$ and the solid solubility limit for $\mathrm{Cu}$ in $\mathrm{Al}$ at room temperature is $\sim 5.65 \mathrm{wt} . \%$, there is a large driving force for the precipitation of the $\mathrm{Cu}$ rich second phase.

The microstructure of the conventionally FSPed alloy is shown in Figure 1. There were no noticeable differences within the actively cooled FSP microstructure. The grains in the FSP zone are equiaxed and on average approximately $5-10 \mu \mathrm{m}$ in diameter, with some grains nearing the sub-micron size range. The structure is very homogeneous, with the large precipitates and defects broken apart. This type of structure appears to enhance the ductility even at room temperatures. In fact, Mishra et al. have shown a microstructure in 7075 aluminum similar to the microstructure found in this study to exhibit high strain rate superplasticity at $490^{\circ} \mathrm{C}$ [10]. Clearly, FSP has great potential in aiding manufacturing by helping to create near net shape parts. This benefit can be further increased by elevating the alloys to modest temperatures.

The microhardness profile shown in Figure 2 clearly shows a large drop in hardness within the FSP zone of the plates. In both conventionally processed and actively cooled plates the hardness increases relatively quickly from the FSP zone through the heat affected zone (HAZ) toward the anvil. The actively cooled plate demonstrates a more abrupt hardness gradient compared with the conventionally processed plate. Additionally, the maximum hardness near the anvil for the actively cooled plate is $165 \mathrm{HVN}$, compared with 155 HVN for the conventionally processed plate. The hardness gradient shown in Figure 3 is through the thickness of the plate.

At a cursory glance, one would expect the extremely fine-grained FSP region to have the largest hardness and strength due to the Hall-Petch relationship. Indeed, Kwon et al. reported a hardness increase through the FSP zone in 1050 aluminum [11]. Thus, solid solution precipitation appears to be an extremely important strengthening mechanism for 2519 aluminum. The softening of material in and near the FSP zone is most likely due to the overaging of the $\mathrm{Cu}$ rich second phase inherit
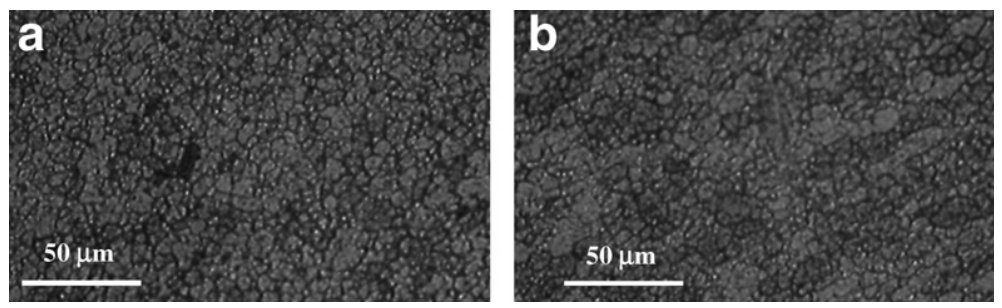

Figure 1. (a) Optical micrographs of the FSP zone in the conventionally processed plate and (b) in the actively cooled plate. (a) and (b) are nearly identical, and show the fine equiaxed grains common in friction stir material with an apparent average grain size of 5-10 $\mu \mathrm{m}$. 


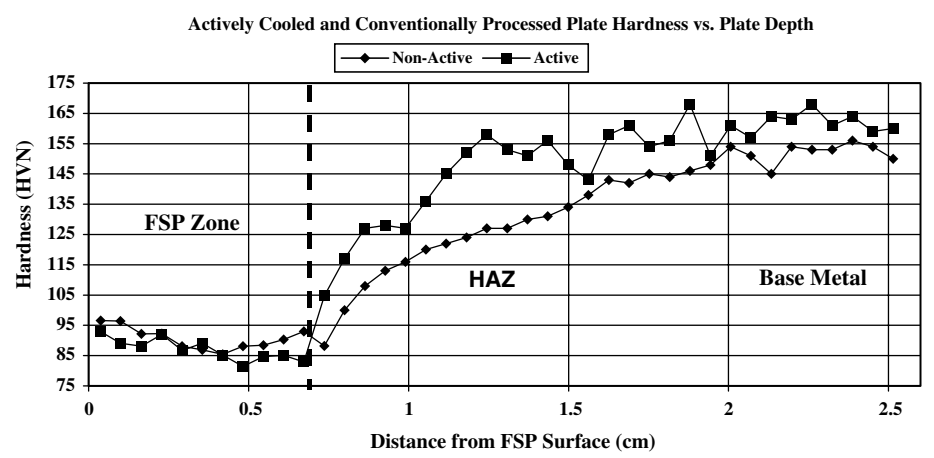

Figure 2. The through thickness hardness profile of both the actively cooled plate and conventionally processed plates shows a dramatic increase in hardness upon leaving the FSP zone. The actively cooled plate recovers its hardness over a shorter distance relative to the conventionally processed plate. The dashed line indicates the border between the FSP zone and the HAZ.

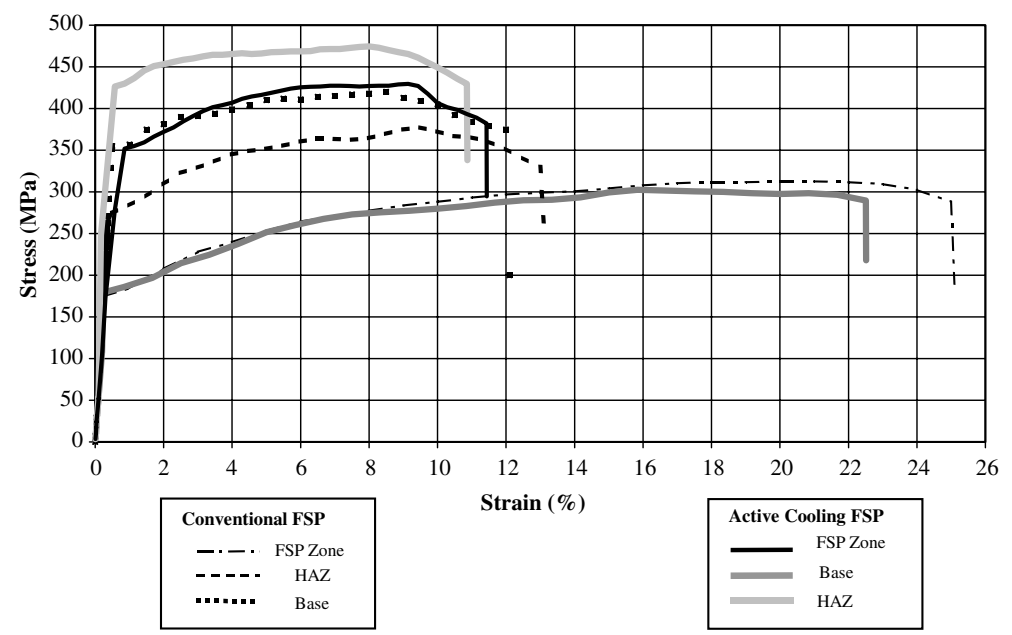

Figure 3. Representative curves of the room temperature tensile tests. Note the large increase in ductility and depressed strength in the FSP zone of both actively cooled and conventionally FSP plates.

in this alloy. In this case, hardness appears to be a function of the amount of heat the plate experienced. This would explain why the actively cooled plate recovers its hardness more quickly and more completely than the conventionally processed plate. Similar softening phenomena have been reported in the literature for precipitation hardened aluminum alloys [8,12-14].

The results of the tensile tests are shown in Figure 3, while Figure 4 shows the results of the room temperature bending test.

The top plate has been actively cooled and fractured at an angle of $22^{\circ}$ while the bottom conventionally processed plate was successfully bent to an angle of $30^{\circ}$. In both cases the FSP zone is adjacent to the top of the plates where the strain is the greatest. Plates that did not see FSP failed at bend angles of less than $5^{\circ}$. To the authors' knowledge this is the first time thick section bending has been demonstrated in 2519-T87 aluminum.

As was expected, the FSP zone was much more ductile and had a lower yield strength as compared with the HAZ and base metal regions of the plate. The reasons for lower strength are the same as the reasons for the depressed hardness discussed above. The enhanced ductility found in FSP aluminum is most likely caused by

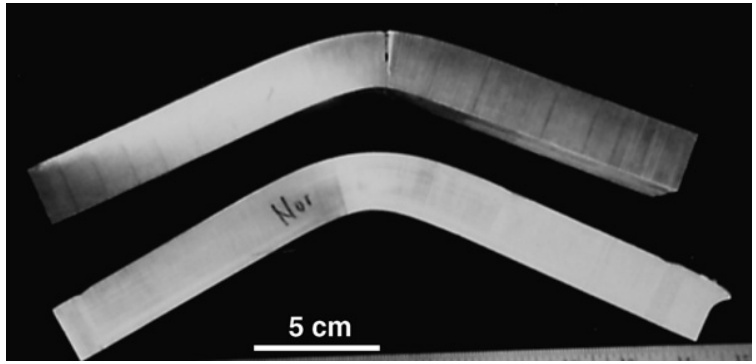

Figure 4. The results of the room temperature bend test of the inch thick plate. The top plate was actively cooled and fractured while the bottom plate was conventionally processed. The top surfaces of both plates were completely FSPed to a depth of $7 \mathrm{~mm}$.

increased dislocation mobility, not grain boundary sliding (GBS). GBS at room temperatures is highly unlikely in this alloy due to the lack of diffusional mass transport to accommodate the stresses at grain boundary triple points. The increase in dislocation mobility is due to the coarser, more broadly distributed, overaged precipitates found in and near the FSP zone, and accounts for the vast majority of the enhanced ductility. Mahoney et al. have shown that the grains found in FSP/FSW aluminum have the necessary misorientation and high 
angles to allow for GBS [10]. It is therefore likely that this FSP alloy is superplastic at temperatures over $400{ }^{\circ} \mathrm{C}$. Nevertheless, thick section bending at room temperatures is possible in 2519 , but only because of the enhanced ductility garnered by the increased dislocation mobility not due to GBS. The reason the actively cooled plate failed is simply related to the decrease in the size of the more ductile HAZ through the thickness of the plate.

In general, the actively cooled FSP plate is stronger and less ductile than the conventionally processed plate. Actively cooling the plate resulted in a more abrupt hardness gradient through the thickness of the plate and stronger base metal. Additionally, strength is related to the frictional processing temperatures. The zones that saw the most heat were the most ductile. Ductility in the FSP zone is due not to GBS but to the enhanced dislocation mobility related to the larger, more broadly distributed $\mathrm{CuAl}_{2}$ precipitates in the aluminum matrix. This enhanced ductility can be used to bend thick sections of 2519-T87 plate at room temperature.

The authors are grateful for the use of the testing facilities at California Polytechnic, for the material supplied by Rockwell Scientific and for the experimental assistance provided by the staff at Rockwell Scientific.

[1] M.W. Thomas, E.D. Nicholas, J.C. Needham, M.G. Murch, P. Templesmith, C.J. Dawes, Friction Stir Butt
Welding. GB Patent Application No. 9125978.8, December 1991; US Patent No. 5460317, October 1995.

[2] C.J. Dawes, W. Thomas, TWI Bulletin 6 (November/ December) (1995) 124.

[3] R.S. Mishra, M.W. Mahoney, S.X. McFadden, N.A. Mara, A.K. Mukherjee, Scripta Mater. 42 (2000) 163.

[4] R.S. Mishra, M.W. Mahoney, Mater. Sci. Forum 357-359 (2001) 507

[5] R.S. Mishra, Z.Y. Ma, Mater. Sci. Eng. R 50 (2005) 1.

[6] Alcoa Mill Products, Inc. Alloy 2519-T87 Technical Data. Alcoa, Bettendorf, IA, 1990.

[7] C.G. Rhodes, M.W. Mahoney, B. Bingel, R.A. Spurling, C.C. Bampton, Scripta Mater. 36 (1997) 69.

[8] G. Liu, L.E. Murr, C.S. Niou, J.C. McClure, F.R. Vega, Scripta Mater. 37 (1997) 355.

[9] ASTM Annual Book of Standards 2001, Section 3, vol. 03.01, Metals Mechanical Testing 2001; pp. 56-78.

[10] Z.Y. Ma, R.S. Mishra, M.W. Mahoney, Acta Mater. 50 (2002) 4419.

[11] Y.J. Kwon, I. Shigematsu, N. Saito, Scripta Mater. 49 (2003) 785 .

[12] S. Benavides, Y. Li, L.E. Murr, D. Brown, J.C. McClure, Scripta Mater. 41 (1999) 809.

[13] Y. Li, L.E. Murr, J.C. McClure, Mater. Sci. Eng. A 271 (1999) 213.

[14] Y.S. Sato, H. Kokawa, M. Enmoto, S. Jogan, Metall. Mater. Trans. A 30 (1999) 2429. 